Research

\title{
A Korean version of the Oral Impacts on Daily Performances (OIDP) scale in elderly populations: Validity, reliability and prevalence \\ Se-Hwan Jung ${ }^{\dagger 1}$, Jae-In Ryu*2, Georgios Tsakos ${ }^{\dagger 2}$ and Aubrey Sheiham ${ }^{\dagger 2}$
}

\author{
Address: ${ }^{1}$ Department of Preventive and Public Health Dentistry, Kangnung National University, Gangneung, Republic of Korea and ${ }^{2}$ Department \\ of Epidemiology and Public Health, University College London, London, UK \\ Email: Se-Hwan Jung - feeljsh@kangnung.ac.kr; Jae-In Ryu* - jaeinryu@yuhs.ac; Georgios Tsakos - g.tsakos@ucl.ac.uk; \\ Aubrey Sheiham - a.sheiham@ucl.ac.uk \\ * Corresponding author †Equal contributors
}

Published: 27 February 2008

Health and Quality of Life Outcomes 2008, 6:17 doi:10.1 186/1477-7525-6-17
Received: 8 June 2007

Accepted: 27 February 2008

This article is available from: http://www.hqlo.com/content/6/1/17

(C) 2008 Jung et al; licensee BioMed Central Ltd.

This is an Open Access article distributed under the terms of the Creative Commons Attribution License (http://creativecommons.org/licenses/by/2.0), which permits unrestricted use, distribution, and reproduction in any medium, provided the original work is properly cited.

\begin{abstract}
Background: This study aimed to develop a Korean version of the OIDP index for elderly people and to assess the levels of sociodental impacts in an older Korean population.

Methods: The OIDP index for elderly people was cross-culturally adapted from English into Korean and then the derived instrument was tested for reliability and validity. The study population was elderly (65+ year-old) residents of Gangneung City, South Korea. Twenty two of the 222 senior day centres were randomly selected.

Results: 687 people were invited and 668 participated in the study (response rate: 97.2\%). The standardized Cronbach's alpha coefficient was 0.85 . The OIDP related significantly with different subjective measures of oral and general health $(\mathrm{p}<0.00 \mathrm{I}) .62 .9 \%$ of the people had oral impacts relating to one or more performances, with eating food being the most frequently affected performance (47.6\%). More than $70 \%$ of people with oral impacts had up to 3 performances affected by oral health conditions.

Conclusion: The Korean OIDP index showed satisfactory validity and internal consistency reliability, confirming its appropriateness for use among older Korean people. The prevalence of oral health related impacts was high. Future studies should focus on the test-retest reliability and the sensitivity to change of the Korean OIDP.
\end{abstract}

\section{Background}

National dental surveys aim to provide planners and policy makers with sound data for planning dental services. Unfortunately, most surveys only use conventional normative oral health indices $[1,2]$. Such clinical indicators frequently overestimate oral health needs [3]. More comprehensive measures, including socio-dental indicators which have been developed to overcome this problem [4], should be used. They complement clinical measurements and measure a range of dimensions of Oral HealthRelated Quality of Life (OHRQoL) including oral health impairments, functional limitation, and disability $[2,5,6]$. The virtue of OHRQoL measures is that they highlight the importance of the oral impacts and give planners insights into the subjective feelings of the population. 
The Oral Impacts on Daily Performance (OIDP) [7] is one of the most widely used sociodental indicators. The theoretical framework on which the OIDP is based is modified from the WHO's [8] International Classification of Impairments, Disabilities and Handicaps [9]. The main modification is that different levels of the concepts are established: oral status or impairments, intermediate impacts (pain, discomfort, functional limitation or dissatisfaction with appearance), and ultimate impacts which cover the concepts of disability and handicap. The OIDP focuses on the third level of measurement, thus assessing oral impacts on the ability to perform daily activities. It is easy to use and has been successfully tested for reliability and validity in adult and elderly populations in different settings $[7,10-15]$. Before using an OHRQoL measure in a new setting, it is necessary to re-establish its psychometric properties. Therefore, the first objective of this study is to develop and validate a Korean version of the OIDP index for elderly people. The second objective is to assess the levels of sociodental impacts in an older Korean population.

\section{Methods}

The research sites for this study were located in Gangneung City, the North-East of South Korea. The study population was residents of this city, aged over 65 years. The sampling frame referred to the 222 senior day centres of the city. These are places where retired free-living senior adults meet, communicate and participate in recreational activities. Twenty two of the 222 senior day centres were randomly selected for this study.

To cross-culturally adapt the OIDP for use among Korean elderly people, the English OIDP index for elderly people [15] was first translated into Korean by three independently working Korean scholars with a good knowledge of English. Because $19.2 \%$ of the elderly are illiterate in Korea [16], the Korean version of the OIDP index needed to be a questionnaire for face to face interviews. The translated questionnaire was first tested on 20 people in a senior day centre. After the interviews, the interviewers had informal conversations with the participants about the questionnaire. Minor modifications were made to the format of questionnaires and to the wording. Secondly, the backward translation of the draft version of the Korean OIDP into English was carried out by experts in foreign languages at the Institute of Kangnung National University in Korea. Then, experts on dental public health, language and translation compared the back translation with the original English version of questionnaire. Finally, the backward translation of English OIDP was verified with the original developers of the OIDP at University College London.
A second pilot study was carried out prior to the main study to test the feasibility of questionnaire administration under field conditions, as well as the understanding of the content of the questionnaire under investigation. Another 20 elderly people from a senior day centre participated in this pilot testing of the oral health assessment and questionnaire forms. The pilot study confirmed the feasibility of the methodology with some modifications.

An examiner was trained and calibrated to the 2000 and 2003 National Oral Health Survey. He was fully aware of the form and criteria for the oral examination of National Survey. The interviewers were briefed about the purpose and process of the study. They had experience in interviewing people for oral health related questionnaires and had worked in Kangnung Dental College as researchers. The manual for the interviewers of the OIDP was completed based on the discussion from pilot tests.

The main study was implemented on elderly people attending 22 senior day centres. Information letters were sent to the selected senior day centres at least one week prior to the date of the data collection. Data were collected using the clinical oral health assessment form and the oral health questionnaires. Clinical dental examinations were used to determine whether subjects were dentate or edentulous, count the number of natural teeth present and assess the need for restorative and prosthetic treatment. The oral health questionnaire recorded data on demographic information, perceived oral health conditions, satisfaction with oral health status, perceived general health conditions, and pain using a visual analogue scale (VAS). A Visual Analogue Scale is a measurement instrument that tries to measure a characteristic or attitude that is believed to range across a continuum of values and cannot easily be directly measured [17].

The study was ethically approved by the Institutional Review Board (IRB) in Kangnung National University Dental College (IRB Letter No. 2004-02). Individual positive consent was sought for the clinical oral examination and the questionnaire-led interview. Subjects were free to withdraw from the study at any stage. Local city councils and health authorities in the study areas were contacted to gain permission and co-operation. Every participant received information on their measured oral and general health conditions.

\section{Data analysis}

Each performance score of OIDP was calculated by multiplying frequency $(0-5)$ and severity scores $(0-5)$. Then these scores for the 10 performances were summed up. Finally the overall OIDP score was the sum divided by maximum possible score ( 5 frequency $\times 5$ severity scores $\times 10$ performances) and multiplied with 100 to give a per- 
centage score. In addition to the OIDP score, the extent of OIDP impacts was also reported. This is an alternative way of quantifying oral impacts, previously suggested for the OIDP [18] and used in the Child-OIDP [19], and refers to the number of OIDP performances with impacts (PWI) affecting a respondent's quality of life over the past six months.

Face and content validity were tested in the pilot study with regard to content, wording, scoring method, and easiness and appropriateness of the questionnaire administration. Content validity measures whether the components of the scale or item cover all aspects of the attribute to be measured or the content of the variables matches the name which it has been given [20]. The criterion validity is defined as the correlation of a scale with some other measure of the trait under study, ideally a 'gold standard', while the construct validity, described as probably the most important approach to validity $[21,22]$, tests logical constructs by assessing the relationship of the instrument under test with measures of other related constructs. As the OIDP is intended to be used in dental needs assessment, perceived need for dental treatment was chosen as a proxy measure for the criterion validity testing, while pain visual analogue scales, perceived oral health status, satisfaction with oral health status and perceived general health status for the construct validity testing [23] of the Korean OIDP. Due to their skewed frequency distribution, the pain VAS scores were categorised into three, none (0), low (1-5), and high (6-10) pain experience. The OIDP scores were not normally distributed and the Kruskal-Wallis test was used for analyzing the relationship between OIDP scores and subjective questions. In addition, the Spearman's rank correlation coefficient was used for the association between the OIDP scores and the pain VAS scores. Internal reliability of the OIDP was tested by inter-item correlations, corrected item-total correlations, standardised alpha coefficient and alpha if item deleted [24]. Finally, the relationships between the OIDP scores and clinical measures of restorative and prosthetic treatment needs were assessed through the use of Kruskal-Wallis test. Treatment need variables were categorised into three groups: 1) restorative treatment needs: no need, one surface restoration, pulp care with restoration or extraction; and 2) prosthetic treatment needs: no need, need only in one jaw, needs in both jaws. SPSS version 13.0 for Windows was used for the analysis of data in this sample. The cut-off level for statistical significance was 0.05 [25].

\section{Results}

687 people were invited to participate in this study and 668 agreed with a response rate of $97.2 \%$. The sociodemographic distribution of the sample is shown in Table 1. The age ranged from 65 to 93 and the mean of it was 75.5
Table I: Socio-demographic characteristics of the Korean elderly subjects $(n=668)$

\begin{tabular}{llr}
\hline Demographic information & Percent \\
\cline { 2 - 2 } Age & 65-74 years & 46.7 \\
Sex & over 75 years & 53.3 \\
& male & 49.1 \\
Household status & female & 50.9 \\
& living alone & 23.1 \\
& living with your husband/wife & 42.8 \\
& living with children & 33.7 \\
Education & other & 0.4 \\
& no formal education & 43.0 \\
& primary school & 42.8 \\
& middle school & 6.7 \\
& high school & 6.4 \\
& college & 1.0
\end{tabular}

\pm 6.0 years. There were slightly more females than males. Most participants had not finished elementary school $(86 \%)$. More than half of the people had dentulous dentitions in both jaws and around a quarter of the study sample was totally edentulous (Table 2). The mean number of permanent natural teeth present was $11.6 \pm$ 9.8. Clinically $36.4 \%$ of subjects were assessed to need restorative treatment, while in terms of prosthetic treatment $23.5 \%$ of needed treatment in one jaw and $20.7 \%$ in both jaws. $64.6 \%$ of the respondents thought they need dental treatments and $62.4 \%$ answered that they have poor oral condition. Slightly less than half of the subjects $(43.1 \%)$ were satisfied with their oral conditions.

The criterion and construct validity of OIDP index were assessed through its association with several subjective health status variables (Table 3 ). Participants with perceived needs for dental treatment had much higher OIDP scores than those who did not have perceived need for treatment $(\mathrm{p}<0.001)$. Similarly, people who reported worse oral health perceptions or had higher pain VAS scores had significantly higher OIDP scores than their counterparts with better oral health perceptions or lower pain scores respectively ( $\mathrm{p}<0.001$ for both). The association between pain VAS score and the OIDP score was also significant $(\mathrm{p}<0.001)$, with a relatively strong correlation coefficient of 0.42 . In relation to construct validity tests, people with higher levels of satisfaction with oral health and perceived general health status had lower OIDP scores than those with lower levels of satisfaction and perceived general health status respectively $(\mathrm{p}<0.001)$. All those relationships showed a clear trend with OIDP scores, not only a difference between the extreme groups; the worse the perception, the higher the OIDP score, which indicates higher level of oral impacts. 
Table 2: Percentage distribution of clinical and subjective status in Korean elderly subjects $(n=668)$

\begin{tabular}{|c|c|c|}
\hline Clinical status and needs & Categories & Percent \\
\hline \multirow[t]{4}{*}{ Denture status } & both edentulous & 22.5 \\
\hline & upper edentulous & 14.7 \\
\hline & lower edentulous & 3.7 \\
\hline & both dentulous & 59.1 \\
\hline \multirow[t]{4}{*}{ Number of natural teeth } & 0 & 22.5 \\
\hline & $1-10$ & 27.2 \\
\hline & $\mathrm{II}-20$ & 23.8 \\
\hline & 21 or more & 26.5 \\
\hline \multirow[t]{3}{*}{ Restorative need } & no need & 63.6 \\
\hline & one surface & 7.7 \\
\hline & $\begin{array}{l}\text { pulp care + restoration } \\
\text { or extraction }\end{array}$ & 28.7 \\
\hline \multirow[t]{3}{*}{ Prosthetic need } & no need & 55.8 \\
\hline & in one jaw & 23.5 \\
\hline & both jaws & 20.7 \\
\hline Subjective status and needs & Categories & Percent \\
\hline \multirow{5}{*}{$\begin{array}{l}\text { Perceived dental treatment } \\
\text { need' }\end{array}$} & no need at all & 8.9 \\
\hline & no need & 26.4 \\
\hline & fairly need & 9.8 \\
\hline & need & 29.0 \\
\hline & high level of need & 25.8 \\
\hline \multirow[t]{4}{*}{ Perceived oral health ${ }^{2}$} & good & 18.5 \\
\hline & fair & 19.1 \\
\hline & poor & 34.6 \\
\hline & very poor & 27.8 \\
\hline \multirow[t]{3}{*}{ Pain VAS (categorised) } & 0 & 65.4 \\
\hline & $\mathrm{I}-5$ & 21.0 \\
\hline & $6-10$ & 13.6 \\
\hline \multirow{4}{*}{$\begin{array}{l}\text { Satisfaction with oral health } \\
\text { status } 3\end{array}$} & satisfied & 23.4 \\
\hline & fairly satisfied & 19.7 \\
\hline & not satisfied & 31.1 \\
\hline & not at all satisfied & 25.8 \\
\hline \multirow[t]{4}{*}{ Perceived general health ${ }^{3}$} & good & 18.0 \\
\hline & fair & 25,2 \\
\hline & poor & 30.0 \\
\hline & very poor & 26.7 \\
\hline
\end{tabular}

I Due to missing cases, analysis carried out on 651 people.

2 Due to missing cases, analysis carried out on 665 people.

${ }^{3}$ Due to missing cases, analysis carried out on 666 people.

In addition, the OIDP was able to discriminate between participants with different degrees of treatment needs. The relationship between the OIDP score and restorative treatment need showed significant trend $(p=0.016)$, with worse OHRQoL among participants in higher need for treatment. Furthermore, the relationship between OIDP score and prosthetic treatment need of participants showed a similar pattern $(\mathrm{p}<0.001)$; the mean OIDP score among subjects with no prosthetic need was 6.3, while the figures among those with need in one jaw and need in both jaws were 9.0 and 10.4 respectively.

Table 4 shows that the inter-item correlation coefficients among the 10 items scores of the OIDP index ranged from 0.13 to 0.74 . None of the scores were negative suggesting that the items were homogenous. Also, the correlations were not high enough for any item to be redundant. Corrected item-total correlations coefficients ranged from 0.40 to 0.68 (Table 5). Cronbach's alpha coefficient was 0.84 and the standardized alpha was 0.85 . When any of the items was deleted the alpha coefficient did not override the standardized alpha.

A relatively high percentage of people (62.9\%) reported oral impacts relating to one or more performances. The distribution of people with oral impacts for the different performances is shown in Table 6 . The most frequently affected performance was eating food (47.6\%). The next most common impacts related to speaking $(24.9 \%)$ and cleaning teeth (19.3\%). The extent of oral impacts ranged from 0 to 10 performances with impacts (PWIs). More than $70 \%$ of people with oral impacts had up to three performances affected from oral conditions; $36.7 \%$ had 1 PWI, $21.2 \%$ had 2 PWIs, and $15.7 \%$ had 3 PWIs (Figure $1)$.

\section{Discussion}

This is the first study to adapt the OIDP index in Korean and test its validity and reliability on an elderly Korean population. Considerable efforts were devoted to the appropriate cross-cultural adaptation of the instrument, in order to overcome the language and cultural differences. Failure to deal with those issues can raise critical questions on the validity of an adapted version of an index [26]. Structured translation is one of the most important procedures to avoid this problem. This study followed the methodology from previous studies on the OIDP $[6,12,15,27,28]$. The professional language unit, consisting of staff who can speak both English and Korean fluently, undertook the forward and backward translation. After that the draft was re-examined twice in pilot studies.

The pilot study provided insights into the understanding of Korean version of OIDP by Koreans. For example, they confused the meaning of 'sleeping' because it could be interpreted as 'sleeping' or 'going to bed' which are the same word in Korean. 'Sleeping' was complemented with extra explanation of this performance. Second, some of 
Table 3: Criterion and construct validity tests for Korean elderly OIDP index and relationship with clinical measures: OIDP scores $(0-100)$ between different categories of outcome measurements

\begin{tabular}{|c|c|c|c|c|c|c|}
\hline Variables & Categories & $\mathbf{N}$ & Mean & (SD) & Quartiles & $\mathbf{P}$ \\
\hline \multicolumn{7}{|l|}{ Subjective health status measures } \\
\hline \multirow[t]{5}{*}{ Perceived dental treatment need $(n=65 \mathrm{I})$} & no need at all & 58 & 0.9 & $(2.8)$ & $(0.0,0.0,0.0)$ & $<0.001$ \\
\hline & no need & 172 & 3.4 & $(9.1)$ & $(0.0,0.0,2.2)$ & \\
\hline & fair level of need & 64 & 3.6 & (7.3) & $(0.0,0.0,3.2)$ & \\
\hline & need & 189 & 6.8 & $(I 1.0)$ & $(0.0,1.8,8.6)$ & \\
\hline & high level of need & 168 & 17.8 & $(20.1)$ & $(2.7,10.2,25.4)$ & \\
\hline \multirow[t]{4}{*}{ Perceived oral health $(n=665)$} & good & 123 & 1.9 & $(6.2)$ & $(0.0,0.0,0.0)$ & $<0.001$ \\
\hline & fair & 127 & 2.3 & $(4.9)$ & $(0.0,0.0,1.6)$ & \\
\hline & poor & 230 & 7.7 & $(13.1)$ & $(0.0,2.2,9.6)$ & \\
\hline & very poor & 185 & 15.8 & $(19.1)$ & $(0.4,10.0,20.6)$ & \\
\hline \multirow[t]{3}{*}{ Pain VAS (categorised) $(n=668)$} & 0 & 437 & 4.5 & $(10.2)$ & $(0.0,0.0,6.0)$ & $<0.001$ \\
\hline & $1-5$ & 140 & 8.7 & $(13.2)$ & $(0.0,2.8,12.0)$ & \\
\hline & $6-10$ & 91 & 22.1 & $(21.3)$ & $(6.0,17.6,31.2)$ & \\
\hline \multirow{4}{*}{ Satisfaction with oral health $(n=666)$} & satisfied & 156 & 1.8 & (6.7) & $(0.0,0.0,0.0)$ & $<0.001$ \\
\hline & fairly satisfied & $|3|$ & 2.5 & $(5.7)$ & $(0.0,0.0,1.6)$ & \\
\hline & not satisfied & 207 & 9.0 & $(13.6)$ & $(0.0,4.0,12.0)$ & \\
\hline & not at all satisfied & 172 & 16.1 & $(19.2)$ & $(1.7,10.0,20.4)$ & \\
\hline \multirow[t]{4}{*}{ Perceived general health $(n=666)$} & good & 120 & 3.4 & $(8.2)$ & $(0.0,0.0,2.0)$ & $<0.001$ \\
\hline & fair & 168 & 7.4 & $(14.5)$ & $(0.0,0.0,8.3)$ & \\
\hline & poor & 200 & 7.7 & $(14.6)$ & $(0.0,0.6,8.4)$ & \\
\hline & very poor & 178 & 11.3 & $(15.7)$ & $(0.0,6.0,16.0)$ & \\
\hline \multicolumn{7}{|l|}{ Clinical dental treatment needs } \\
\hline \multirow[t]{3}{*}{ Restorative need } & no need & 425 & 7.1 & $(13.4)$ & $(0.0,0.0,6.0)$ & $=0.016$ \\
\hline & one surface & 51 & 7.2 & $(13.2)$ & $(0.0,2.0,13.4)$ & \\
\hline & pulp care + restoration or extraction & 192 & 9.6 & $(15.8)$ & $(0.0,3.0,14.0)$ & \\
\hline \multirow[t]{3}{*}{ Prosthetic need } & no need & 373 & 6.3 & $(13.1)$ & $(0.0,0.0,8.0)$ & $<0.001$ \\
\hline & in one jaw & 157 & 9.0 & $(14.4)$ & $(0.0,0.0,10.0)$ & \\
\hline & both jaws & 138 & 10.4 & $(16.0)$ & $(0.0,2.4,12.0)$ & \\
\hline
\end{tabular}

Table 4: Reliability analysis of OIDP index for Korean participants: OIDP items Correlation matrix

\begin{tabular}{|c|c|c|c|c|c|c|c|c|c|c|}
\hline \multirow[b]{2}{*}{ Performances } & \multicolumn{10}{|c|}{ Performances } \\
\hline & $\mathrm{I}$ & 2. & 3. & 4. & 5. & 6. & 7. & 8. & 9. & 10 \\
\hline I. eating & 1.00 & & & & & & & & & \\
\hline 2. speaking & 0.39 & 1.00 & & & & & & & & \\
\hline 3. smiling & 0.30 & 0.48 & 1.00 & & & & & & & \\
\hline 4. light physical activities & 0.39 & 0.35 & 0.22 & 1.00 & & & & & & \\
\hline 5. daily activities & 0.38 & 0.40 & 0.38 & 0.73 & 1.00 & & & & & \\
\hline 6. enjoying contact & 0.37 & 0.53 & 0.48 & 0.52 & 0.74 & 1.00 & & & & \\
\hline 7. cleaning teeth & 0.37 & 0.26 & 0.30 & 0.13 & 0.21 & 0.21 & 1.00 & & & \\
\hline 8. sleeping & 0.27 & 0.25 & 0.16 & 0.26 & 0.32 & 0.29 & 0.29 & 1.00 & & \\
\hline 9. relaxing & 0.34 & 0.21 & 0.21 & 0.42 & 0.37 & 0.35 & 0.28 & 0.41 & 1.00 & \\
\hline 10. emotional stability & 0.53 & 0.44 & 0.43 & 0.49 & 0.48 & 0.54 & 0.32 & 0.30 & 0.42 & 1.00 \\
\hline
\end{tabular}


Table 5: Reliability analysis of OIDP index: Corrected item-total correlation, Cronbach's Alpha, Standardised Alpha and Alpha if item deleted

\begin{tabular}{lcc}
\hline Performances & $\begin{array}{c}\text { Corrected item-total } \\
\text { correlation }\end{array}$ & $\begin{array}{c}\text { Alpha if item } \\
\text { deleted }\end{array}$ \\
\hline 1. eating & 0.57 & 0.83 \\
2. speaking & 0.57 & 0.83 \\
3. smiling & 0.51 & 0.83 \\
4. light physical activities & 0.58 & 0.83 \\
5. daily activities & 0.67 & 0.82 \\
6. enjoying contact & 0.68 & 0.82 \\
7. cleaning teeth & 0.40 & 0.84 \\
8. sleeping & 0.41 & 0.84 \\
9. relaxing & 0.48 & 0.84 \\
10. emotional stability & 0.68 & 0.81 \\
& & \\
Alpha & $=0.84$ & \\
Standardised item Alpha & $=0.85$ & \\
\hline
\end{tabular}

them had difficulties exactly setting the time frame for the reporting of oral impacts when the wording 'in the past 6 months' was used. As a solution the interviewers mentioned the exact month that corresponded to the six months prior to the main study. Those minor modifications improved understanding of the questionnaires and all participants in the main study answered without missing out any item.

The validity of quality of life mainly relied on the subjective measurement. The rationale for this comes from the conceptual distinction between health and disease $[15,29]$. A normative index measures only biological pathology, without considering social and psychological aspects of health. There are well known limitations of the normative assessment of oral health and needs [30]. Disease does not always negatively affect subjective perceptions of wellbeing [15]. Consequently, clinical oral health indicators "tell us nothing about the functioning of either the oral cavity or the person as a whole and nothing about

Table 6: Percentage distribution of people with positive OIDP impacts $(n=668)$

\begin{tabular}{lrr}
\hline Positive OIDP performance & N & $\%$ \\
\hline Any performance affected & 420 & 62.9 \\
Eating & 318 & 47.6 \\
Speaking & 166 & 24.9 \\
Smiling & 97 & 14.5 \\
Light physical activities (housework) & 56 & 8.4 \\
Daily activities (going out) & 64 & 9.6 \\
Enjoying contact & 72 & 10.8 \\
Cleaning teeth & 129 & 19.3 \\
Sleeping & 65 & 9.7 \\
Relaxing & 44 & 6.6 \\
Emotional stability & 128 & 19.2 \\
\end{tabular}

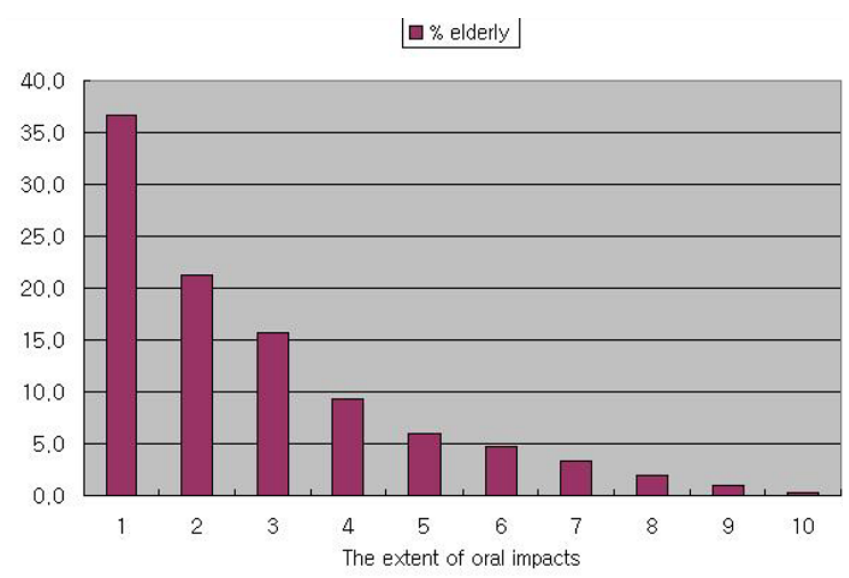

Figure I

Percentage distribution of the number of OIDP performances affected among those with any impact.

subjectively perceived symptoms such as pain and discomfort" [31]. In addition to using the relationship between OIDP and subjective health status measures for the core assessment of validity, the ability of the index was also assessed to discriminate between different clinical status groups.

The results of this study showed that the Korean OIDP for elderly people is a valid and reliable instrument to measure OHRQoL. Face and content validity were confirmed in the pilot study. In this study, all examined relationships between OIDP score and subjective oral health measures (perceived dental treatment need, perceived oral health condition, pain visual analogue scale, satisfaction with oral health) were statistically significant and showed a clear trend in the expected direction; the worse the subjective oral health rating, the higher the OIDP score. Furthermore, in line with previous studies [15,32,33], the OIDP score was significantly associated with perceived general health. In addition to using the relationship between OIDP and subjective health status measures for the core assessment of validity, the ability of the index to discriminate between different clinical groups was successfully assessed. Indeed, the OIDP was able to discriminate between groups with different degrees of treatment need. Subjects with no need for dental treatment reported significantly lower levels of oral impacts than their counterparts with low levels of treatment needs, and those, in turn, had lower levels of impacts than subjects with higher levels of treatment needs. This significant trend was observed in relation to both restorative and prosthetic treatment needs.

Inter-item correlation, corrected item-total correlation, and Cronbach's alpha indicated this index had excellent 
internal consistency. None of the inter-item correlations was negative and all item-total correlations were above the minimum recommended level of 0.20 [34] for including an item in a scale, hence demonstrating the homogeneity of the items. Furthermore, Cronbach's alpha was much higher than the recommended thresholds for research purposes and studying groups and higher than previous studies in other settings $[7,15,27]$.

The overall prevalence of Oral Impacts on Daily Performance (OIDP) was $63 \%$. That was similar to Tanzanian $(62.1 \%)$ [13] and Thai (52.8\%) [14] studies on a similar age group but higher than in other countries $[7,15,27,35]$. The differences in prevalence may be related to cultural differences. The comparison of oral health care systems in six countries reported similar results [36]. There were big differences in subjective oral health conditions. For example, people in Japan, which is close to Korea, were more likely to answer that their oral conditions were not good. It is possible that the cultural gap between western and eastern countries is responsible for the differences. Eating was the most prevalent performance affected by oral impacts among the ten items. That was consistent with the results in other studies $[6,11,13-15,19,27,35,37]$. The performance with the lowest prevalence of oral impacts was relaxing (7\%). Other studies suggested excluding two items such as cleaning and light physical activities which showed the extremely low prevalence from the OIDP [15]. However, our results justify the inclusion of all ten items in the Korean OIDP in future studies, as no item had extremely low prevalence.

The study used simple random sampling from the senior day centres in Gangneung city. The sample may not represent the whole population of Korea. However, the demographic characteristics of this study sample were broadly similar to the rural elderly population in the National Survey, with slightly lower education and income level [16]. The response rate was very high $(97.2 \%)$. This was partly facilitated by the considerable administrative support from the Gangneung City council and health centres, especially as this study was part of a broader endeavour to develop a public oral health plan for the elderly in the area. In addition, study subjects received a free medical and dental examination, which also acted as an incentive to participate. Future studies should also evaluate the testretest reliability of the Korean OIDP, while longitudinal studies would allow for testing its sensitivity to change. Finally, the national Korean oral health survey should include a subjective measure of oral impacts as one of its health measures.

\section{Conclusion}

In conclusion, the Korean OIDP index showed valid and reliable psychometric properties, confirming its appropri- ateness to measure the OHRQoL of older Korean people. The prevalence of oral impacts was high, with eating food being the most frequently affected performance. Future studies should focus on the test-retest reliability and the sensitivity to change of the Korean OIDP.

\section{Abbreviations}

Oral Impacts on Daily Performances (OIDP); Oral Health-Related Quality of Life (OHRQoL); Visual Analogue Scale (VAS); Institutional Review Board (IRB); Performances with Impacts (PWIs)

\section{Competing interests}

The author(s) declare that they have no competing interests.

\section{Authors' contributions}

SHJ contributed to make a conception and design of the study, acquisition of data, analysis and interpretation of data, and drafting the manuscript.

JIR participated in a conception and designing of the study, analysis and interpretation of the data, and drafting the manuscript.

GT advised on the study design and analysis and participated in the interpretation of the data and discussion of the findings.

AS advised on the study design and analysis and participated in the interpretation of the data and discussion of the findings.

All authors read and approved the final manuscript.

\section{Acknowledgements}

The authors acknowledge the help and contribution of professor DeukSang Ma and professor Deok-Young Park, and the people in health centre of Gangneung city. Part of the research was financed by Korean Institute of Oral Health Services.

\section{References}

I. Cushing AM, Sheiham A, Maizels J: Developing socio-dental indicators - the social impact of dental disease. Community Dent Health 1986, 3(1):3-17.

2. Locker D: Measuring oral health: a conceptual framework. Community Dent Health 1988, 5(I):3-18.

3. Wilson IB, Cleary PD: Linking clinical variables with healthrelated quality of life. A conceptual model of patient outcomes. JAMA I995, 273(1):59-65.

4. Slade GD: Measuring oral health and quality of life. Chapel Hill: University of North Carolina: Dental Ecology; 1997.

5. Chen MS, Hunter P: Oral health and quality of life in New Zealand: a social perspective. Social Science \& Medicine (I982) 1996, 43(8): $1213-1222$.

6. Sheiham A, Steele JG, Marcenes W, Tsakos G, Finch S, Walls AW: Prevalence of impacts of dental and oral disorders and their effects on eating among older people; a national survey in Great Britain. Community Dent Oral Epidemiol 200I, 29(3): 195-203. 
7. Adulyanon S, Sheiham A: Oral impacts on daily performances. In Measuring Oral Health and Quality of Life Chapel Hill: University of North Carolina; 1997:151-160.

8. World Health Organisation: International classification of impairments, disabilities and handicaps. Geneva World Health Organisation 1980.

9. Adulyanon S, Sheiham A, Slade GD: Oral impacts on daily performances. In Measuring Oral Health and Quality of Life Chapel Hill: University of North Carolina; 1997: I5 I-160.

10. Astrom AN, Haugejorden O, Skaret E, Trovik TA, Klock KS: Oral Impacts on Daily Performance in Norwegian adults: validity, reliability and prevalence estimates. Eur J Oral Sci 2005, I I 3(4):289-296.

II. Dorri M, Sheiham A, Tsakos G: Validation of a Persian version of the OIDP index. BMC oral health 2007, 7:2.

12. Adulyanon S, Vourapukjaru J, Sheiham A: Oral impacts affecting daily performance in a low dental disease Thai population. Community Dent Oral Epidemiol 1996, 24(6):385-389.

13. Kida IA, Astrom AN, Strand GV, Masalu JR, Tsakos G: Psychometric properties and the prevalence, intensity and causes of oral impacts on daily performance (OIDP) in a population of older Tanzanians. Health Qual Life Outcomes 2006, 4:56.

14. Srisilapanan $P$, Sheiham A: The prevalence of dental impacts on daily performances in older people in Northern Thailand. Gerodontology 2001, I 8(2): I02-108.

I5. Tsakos G, Marcenes W, Sheiham A: Evaluation of a modified version of the index of Oral Impacts On Daily Performances (OIDP) in elderly populations in two European countries. Gerodontology 200I, I 8(2): I 2 I-130.

16. Korean Institute for Health and Social Affairs, Ministry of Health and Welfare: National Survey for living condition and welfare needs of the elderly, Korea 2004. Seoul: Korean Institute for Health and Social Affairs; 2005:199-205.

17. Gould D, Kelly D, Goldstone L, Gammon J: Examining the validity of pressure ulcer risk assessment scales: developing and using illustrated patient simulations to collect the data. J Clin Nurs 200I, I 0(5):697-706.

18. Robinson PG, Gibson B, Khan FA, Birnbaum W: Validity of two oral health-related quality of life measures. Community Dentistry and Oral Epidemiology 2003, 3 I (2):90-99.

19. Gherunpong $S$, Tsakos G, Sheiham A: The prevalence and severity of oral impacts on daily performances in Thai primary school children. Health Qual Life Outcomes 2004, 2:57.

20. Bowling A: Theory of measurement. In Measuring Health - A review of quality of life measurement scales Volume 2. Buckingham: Open University Press; 1997:9-15.

21. MacDowell I, Newell C: The theoretical and technical foundations of health measurement. In Measuring health: a guide to rating scales and questionnaires Oxford: Oxford University Press; 1987.

22. Slade GD, Strauss RP, Atchison KA, Kressin NR, Locker D, Reisine ST: Conference summary: assessing oral health outcomes measuring health status and quality of life. Community Dent Health 1998, I 5(I):3-7.

23. Streiner DL, Norman GR: Validity. In Health Measurement Scales: $A$ Practical Guide to Their Development and Use Volume 2. Oxford: Oxford University Press; 1998: |45-162.

24. Bowling A: Comments on measurement issues and sources of information. In Measuring Disease Open Univeristy Press; 1995:29|-293.

25. Altman DG: Practical statistics for medical research. London: Chapman and Hall; 1994.

26. Allison P, Locker D, Jokovic A, Slade G: A cross-cultural study of oral health values. J Dent Res 1999, 78(2):643-649.

27. Astrom AN, Haugejorden O, Skaret E, Trovik TA, Klock KS: Oral Impacts on Daily Performance in Norwegian adults: validity, reliability and prevalence estimates. Eur J Oral Sci 2005, I I 3(4):289-296.

28. Masalu JR, Astrom AN: Applicability of an abbreviated version of the oral impacts on daily performances (OIDP) scale for use among Tanzanian students. Community Dent Oral Epidemiol 2003, 3 I(I):7-14.

29. Locker D, Miller Y: Subjectively reported oral health status in an adult population. Community Dent Oral Epidemiol 1994, 22(6):425-430.

30. Sheiham A, Tsakos G: Oral Health Needs Assessment. In Community Oral health Volume 2. New Malden: Quintessence; 2007:59-79.
31. Locker D: An introduction to Behavioural Science and Dentistry. London: Routledge; 1989.

32. Dolan TA, Gooch BF, Bourque LB: Associations of self-reported dental health and general health measures in the Rand Health Insurance Experiment. Community Dent Oral Epidemiol 1991, 19(I):I-8.

33. Tickle $M$, Craven R, Worthington HV: A comparison of the subjective oral health status of older adults from deprived and affluent communities. Community Dent Oral Epidemiol 1997, 25(3):217-222.

34. Kline P: A handbook of test construction. London: Routledge; 1986.

35. Sanchez-Garcia S, Juarez-Cedillo T, Reyes-Morales H, de la FuenteHernandez J, Solorzano-Santos F, Garcia-Pena C: [State of dentition and its impact on the capacity of elders to perform daily activities]. Salud Publica Mex 2007, 49(3): I73-I8I.

36. Chen MS, Anderson R, Barmes DE, Leclercq MH, Lyttle CS: Comparing oral health care system - a second international collaborative study. Geneva: World Health Organisation 1997.

37. Astrom AN, Okullo I: Validity and reliability of the Oral Impacts on Daily Performance (OIDP) frequency scale: a cross-sectional study of adolescents in Uganda. BMC Oral Health 2003, 3(I):5.
Publish with Biomed Central and every scientist can read your work free of charge

"BioMed Central will be the most significant development for disseminating the results of biomedical research in our lifetime. "

Sir Paul Nurse, Cancer Research UK

Your research papers will be:

- available free of charge to the entire biomedical community

- peer reviewed and published immediately upon acceptance

- cited in PubMed and archived on PubMed Central

- yours - you keep the copyright 